\title{
Study on chip fragmentation and hole quality in drilling of aluminium 6061 alloy with high pressure internal cooling
}

\author{
Ioan Alexandru Popan ${ }^{1,}$, Alina Ioana Popan ${ }^{1}$, Alexandru Carean ${ }^{1}$, Domnita Fratila ${ }^{1}$ and \\ Adrian Trif ${ }^{1}$ \\ ${ }^{1}$ Technical University of Cluj-Napoca, B-dul. Muncii, No. 103-105, Cluj-Napoca, Romania
}

\begin{abstract}
The drilling process is one of the most common processes on many manufacturing areas. It is used for high-quality hole drilling of Aluminium 6061 alloy. In this experimental study precise holes were drilled, using drills with high pressure internal cooling (50 Bar). The influence of the process parameters on holes quality is analysed. Another aspect studied is chip shape and evacuation.
\end{abstract}

\section{Introduction}

Aluminium 6061 alloy is a light metal used in wide applications in aerospace, automotive and other industries [1,2]. The main characteristics of aluminium alloys are: reduced weight and good strength, low-temperature properties and corrosion resistance [3, 4].

Drilling process is one of the often met from all machining processes. To make precise holes in aluminium alloys using drilling process involves some challenges. One of the biggest problems on drilling process is to cool and to lubricate the cutting edge [5]. To solve this problem could be used: flood machining, drilling with internal cooling [6], cryogenic machining [7] and minimum quantity lubrication [8]. Another important aspect on case of aluminium alloy drilling is chip evacuation [9]. Chip evacuation depends by process parameters [10], tool geometry [5], the cooling system and the type of the drilling cycle used [2]. The challenge of this process is to improve the productivity by increasing the process parameters. The most efficient cooling method in case of high productivity drilling is internal cooling with high pressure.

This paper presents an experimental study on precise holes made using drills with high pressure internal cooling (50 Bar). The effects of the main process parameters (feed rate $f_{n}$ and cutting speed $V_{c}$ ) on holes surface roughness is analysed. Another aspect studied is accuracy, chip shape and evacuation.

\section{Cutting tool and workpiece material}

In this experimental research, an Inova Tools type 706090 solid carbide drill was selected (figure 1). The drill is special developed for aluminium and plastic materials cutting. It has

\footnotetext{
${ }^{*}$ Corresponding author: Ioan.POPAN@tcm.utcluj.ro
} 
a $\mathrm{ZrN}$ coating. This 2 -flute drill has a self-cantering $140^{\circ} \mathrm{SU}$ point and the maximum depth of drilling is $5 \mathrm{D}$ (about $49 \mathrm{~mm}$ ).
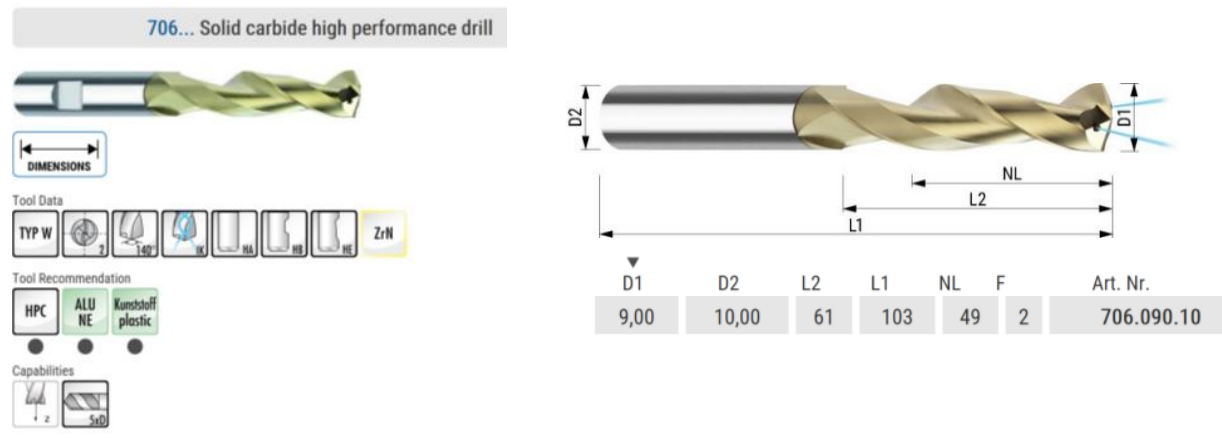

Fig. 1. The carbide drill Inova Tools 706090. [11]

A6061 aluminum alloy was selected for this test. It has max.150 MPa tensile strength and $10-18 \%$ elongation. The alloy composition (reference value \%) is: Al 95.85-98.56, $\mathrm{Zn}$ 0.25, Mg 0.8, Si 0.4, Fe 0.184, Cu 0.15. [2]

\section{Experimental procedure}

The experiment was planned by using the central composite design (CCD) methodology. This methodology CCD is a full factorial designed and in this case was used for two factors. The range of the process parameters analysed in this study is: cutting speed 50-500 $\mathrm{m} / \mathrm{min}$ and feed rate $0.05-0.4 \mathrm{~mm} / \mathrm{rev}$.

The input parameters combination obtained using CCD method, is presented in Table 1. A total of 13 blind holes with $\varnothing 9 \times 20 \mathrm{~mm}$ were produced, according with CCD. The holes were drilled on a $50 \times 50 \times 250 \mathrm{~mm}$ workpiece.

The holes were made using a 3 axis HAAS VF2 machine $(24 \mathrm{~kW}$ motor power and $21,000 \mathrm{rev} / \mathrm{min}$ max. spindle speed). The experiments were carried out by using internal cooling at 50 Bar generated by a high-pressure pomp. To obtain high stiffens during the tests, a mechanical wise was used for fixing the part and a hydraulic tool holder was used to clamp the drill (figure 2).

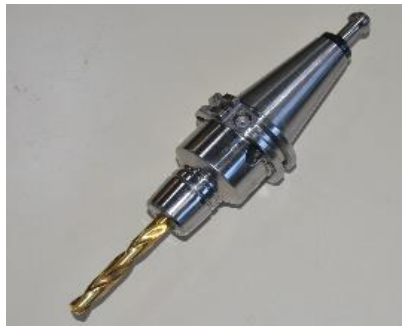

a)

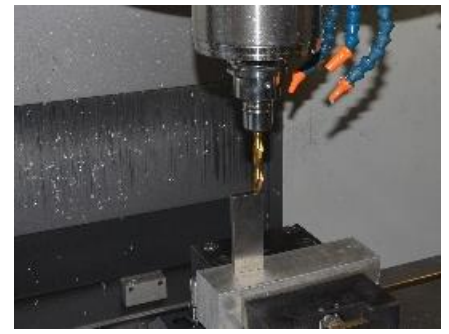

b)

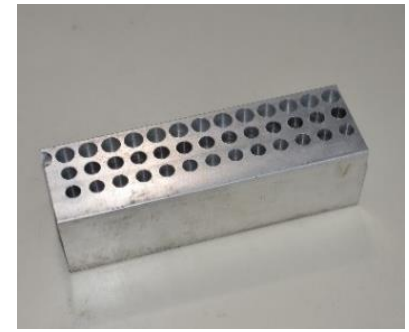

c)

Fig. 2. The experimental setup: a) The tool clamping system; b) The tool measurement; c) The experimental results

For measuring the holes dimensional accuracy, a 3D Aberlink equipment was used. The surface roughness $\left(R_{a}\right)$ was measured using a Mitutoyo Surftest SJ-210. The surface roughness was measured in the middle of the hole and the length was $5 \mathrm{~mm}$. 
The experimental results obtain in this study are presented in table 1. For data processing and analyzing was used Design Expert software.

Table 1. Experimental results.

\begin{tabular}{|c|c|c|c|c|}
\hline No. & $\begin{array}{c}\text { Cutting speed } \\
\boldsymbol{v}_{\boldsymbol{c}}[\mathbf{m m} / \mathbf{m i n}]\end{array}$ & $\begin{array}{c}\text { Feed rate } \\
\boldsymbol{f}[\mathbf{m m} / \mathbf{r e v}]\end{array}$ & $\begin{array}{c}\text { Roughness } \\
\boldsymbol{R}_{\boldsymbol{a}}[\boldsymbol{\mu m}]\end{array}$ & $\begin{array}{c}\text { Dimensional deviation } \\
{[\mathbf{m m}]}\end{array}$ \\
\hline 1 & 115.90 & 0.10 & 12.73 & 0.007 \\
\hline 2 & 434.10 & 0.10 & 2.44 & 0.007 \\
\hline 3 & 115.90 & 0.35 & 2.53 & -0.004 \\
\hline 4 & 434.10 & 0.35 & 11.32 & 0.03 \\
\hline 5 & 50.00 & 0.23 & 5.23 & 0.01 \\
\hline 6 & 500.00 & 0.23 & 4.6 & 0.018 \\
\hline 7 & 275.00 & 0.05 & 4.78 & 0.024 \\
\hline 8 & 275.00 & 0.40 & 33.8 & 0.046 \\
\hline 9 & 275.00 & 0.23 & 3.6 & 0.043 \\
\hline 10 & 275.00 & 0.23 & 12.29 & 0.048 \\
\hline 11 & 275.00 & 0.23 & 2.96 & 0.052 \\
\hline 12 & 275.00 & 0.23 & 6.56 & 0.037 \\
\hline 13 & 275.00 & 0.23 & 11.33 & 0.04 \\
\hline
\end{tabular}

\section{Results and discussions}

Starting from the experimental results obtained in this test, mathematical models was calculated using ANOVA and Response Surface Methodology (RMS). With this mathematical model the variation curves of surface roughness and dimensional deviation was plotted.

Applying the ANOVA / RMS methodology, a mathematical model (a quadratic model) was obtained for surface roughness. Figure 3.a represents the influence of the cutting speed and surface quality. It is obtained by increasing the cutting speed from 115 to $434 \mathrm{~m} / \mathrm{min}$, the surface roughness $\mathrm{Ra}$, decreases from 8.3 up to $3.5 \mu \mathrm{m}$.
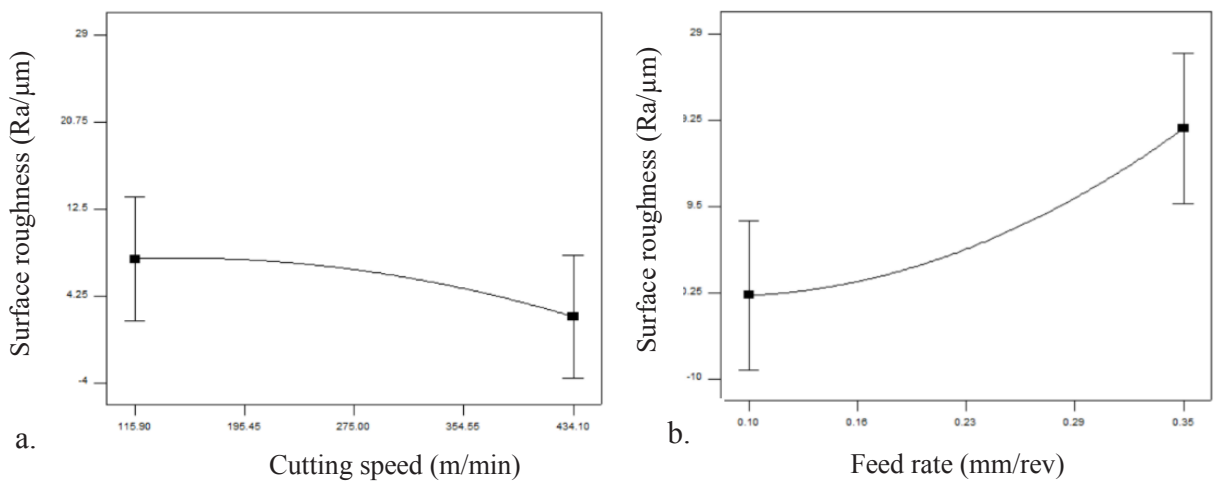

Fig. 3. Effect of cutting parameters on surface quality.

In figure 3.b, the influence of feed rate on surface quality is plotted (cutting speed 150 $\mathrm{m} / \mathrm{min}$ ). Increasing the feed rate from 0.1 to $0.35 \mathrm{~mm} / \mathrm{rev}$, the surface roughness $\mathrm{Ra}$ increases from 0.7 to $1.2 \mu \mathrm{m}$. 
Analysing the hole dimensional deviations obtain in this experimental study a quadratic model was significant, based on ANOVA methodology.

In the graphical representation from figure 4.a, is presented the effect of cutting speed on dimensional deviation. This graphic was obtain using a constant feed rate of $0.3 \mathrm{~mm} / \mathrm{rev}$. By increasing the cutting speed from 100 up to $500 \mathrm{~m} / \mathrm{min}$ resulted that, the dimensional deviation increases from 0.015 to $0.043 \mathrm{~mm}$ and it decreases up to $0.029 \mathrm{~mm}$. The maximal value of dimensional deviation was obtained for a cutting speed of approximately 300 $\mathrm{m} / \mathrm{min}$.
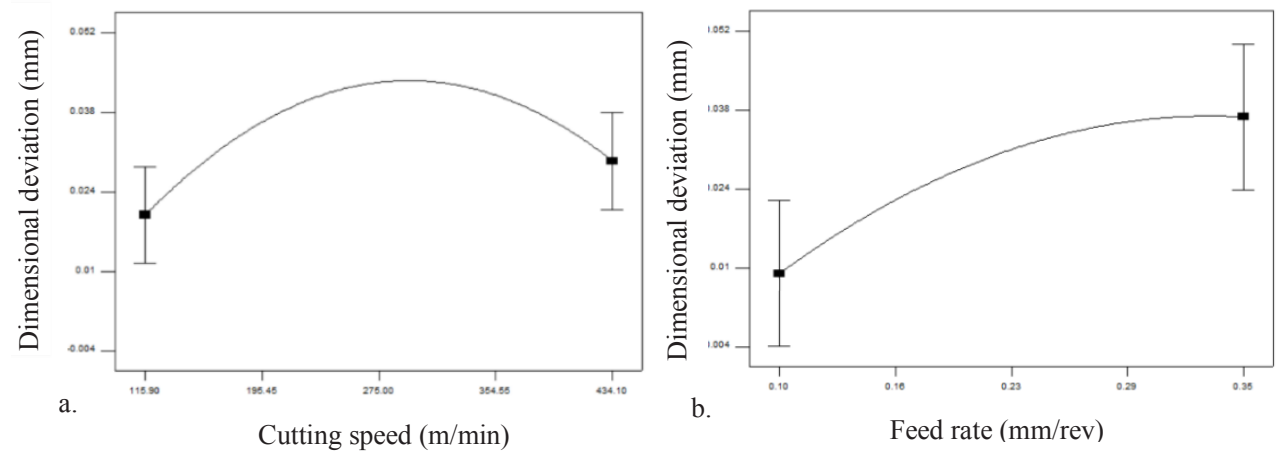

Fig. 4. Effect of cutting parameters on dimensional deviation.

Analysing the influence of feed rate on holes accuracy was obtained the graphical representation from figure 4.b. This graphic was obtained using $150 \mathrm{~m} / \mathrm{min}$ cutting speed. Increasing the feed rate from 0.1 to $0.35 \mathrm{~mm} / \mathrm{rev}$ the dimensional deviation increases from 0.01 up to $0.035 \mathrm{~mm}$. In case of feed rate was observed a linear variation.

\section{Chip shape analysis}

Figure 5 presents the influence of the feed rate on the chip length and width. The study was made using a feed rate of $0.05 ; 0.23$ and $0.4 \mathrm{~mm} / \mathrm{rev}$, cutting speed of $300 \mathrm{~m} / \mathrm{min}$, drilling depth of $20 \mathrm{~mm}$ and internal cooling of 50 Bar.

Figure 5.a shows the chip obtain for $0.05 \mathrm{~mm} / \mathrm{rev}$ feed rate and $300 \mathrm{~m} / \mathrm{min}$ cutting speed. In this case the chip has a spiral form with a length between 10 and $40 \mathrm{~mm}$ and about $8 \mathrm{~mm}$ width. The chip thickness is approximately $0.08 \mathrm{~mm}$.

Increasing the feed rate up to $0.23 \mathrm{~mm} / \mathrm{rev}$ was obtain an arc chip (figure 5.b). The chip dimensions are: $8 \mathrm{~mm}$ length, $6 \mathrm{~mm}$ width and $0.3 \mathrm{~mm}$ thickness.

In the $3^{\text {rd }}$ case analysed, using a feed rate of $0.4 \mathrm{~mm} / \mathrm{rev}$ and a cutting speed of 300 $\mathrm{m} / \mathrm{min}$, a short arc chip was obtained (figure 5.c). The chip dimensions in this case are: 5 $\mathrm{mm}$ length, $4 \mathrm{~mm}$ width and $0.45 \mathrm{~mm}$ thickness.

Using a high-pressure internal cooling (50 Bar) was obtain a good chip evacuation in all three case. The chip obtained in the first case (spiral chip $40 \mathrm{~mm}$ length) could be considered unfavourable, because in normal drilling condition (5-10 Bar internal cooling), it can generate problems of evacuation from deep holes.

The drill cutting edges was analysed using an Optika microscope. It was observed that the wear does not appear on the cutting edges of the drill after 60 holes drilled. In figure 6 is presented the drill cutting edge after experiments. 

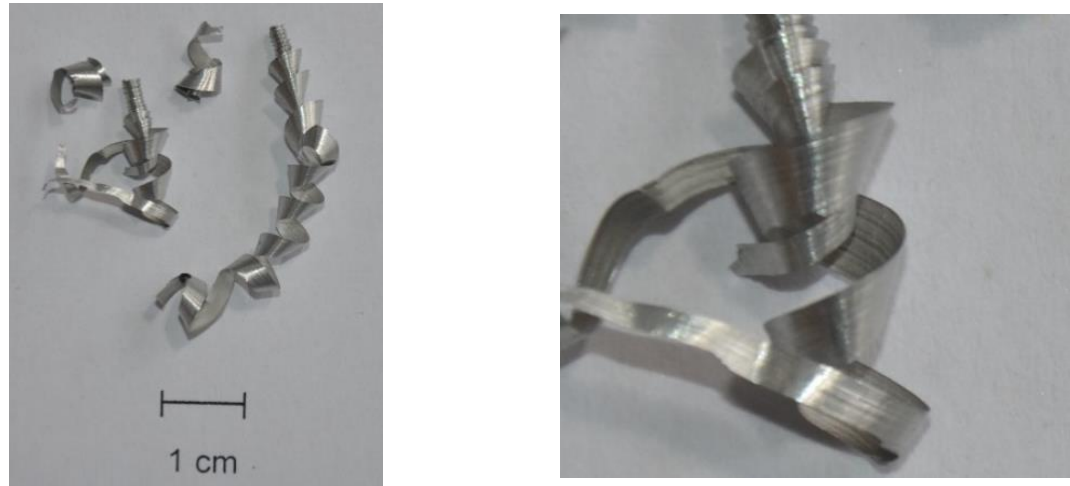

a) $0.05 \mathrm{~mm} / \mathrm{rev}$ feed rate
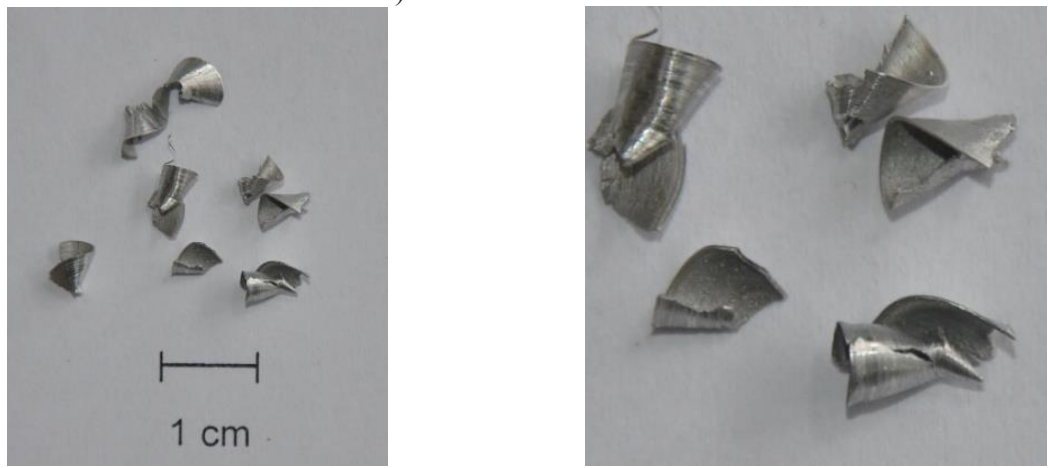

b) $0.23 \mathrm{~mm} / \mathrm{rev}$ feed rate
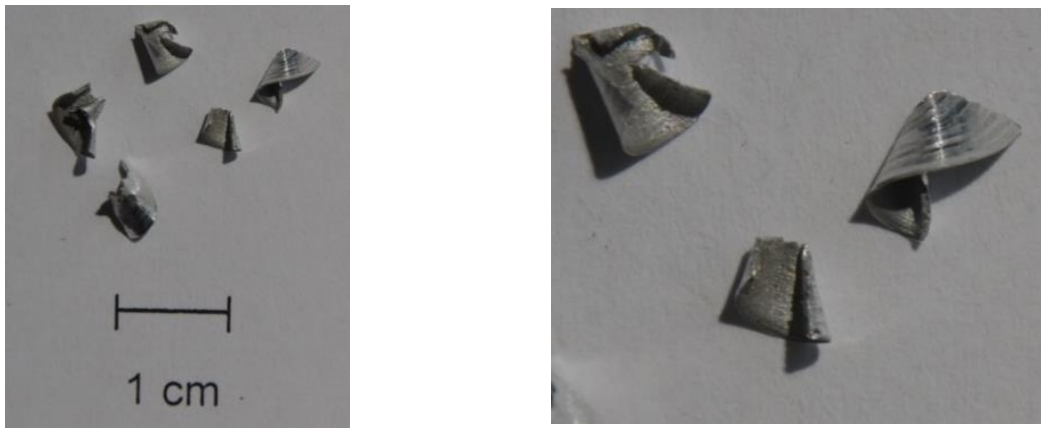

c) $0.4 \mathrm{~mm} / \mathrm{rev}$ feed rate

Fig. 5. The chips obtained in experiment.
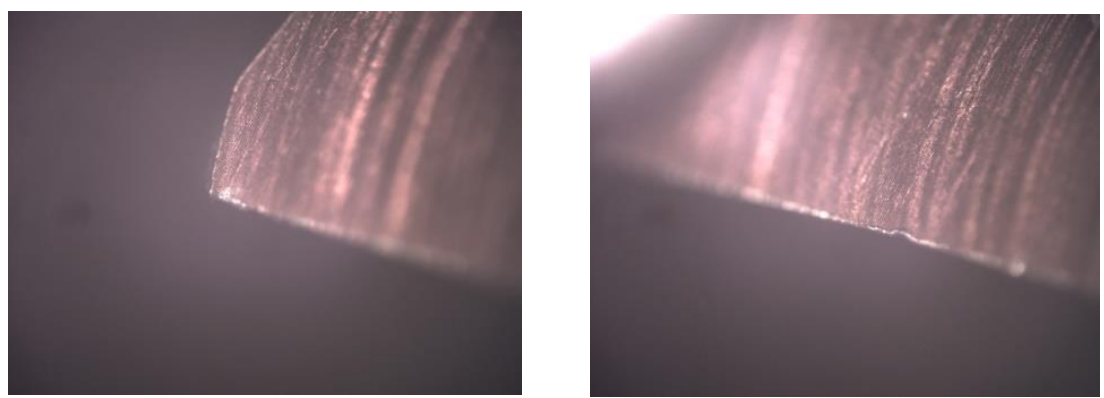

Fig. 6. The drill cutting edge after experiments. 


\section{Conclusions}

In this experimental investigation a new type of carbide drill with high pressure internal cooling of 50 Bar and common aluminium 6061 alloy were involved. The cutting parameters (cutting speed and feed rate) are studied to improve: the accuracy, the surface roughness and the chip evacuation.

The main results are:

- The surface roughness decreases by increasing up to $450 \mathrm{~m} / \mathrm{min}$ the cutting speed and decreasing up to $0.1 \mathrm{~mm} / \mathrm{rev}$ the feed rare.

- In case of dimensional deviation, the biggest effect has the feed rate (up to 0.1 $\mathrm{mm} / \mathrm{rev}$ ), decreasing the dimensional deviation (up to $0.01 \mathrm{~mm}$ ).

- To obtain a small chip dimension (under $8 \mathrm{~mm}$ length and $6 \mathrm{~mm}$ width) and a good chip evacuation, a feed rate over $0.23 \mathrm{~mm} / \mathrm{rev}$ is recommended.

This research was supported by Romanian Ministry of Research and Innovation (UEFISCDI), Project cod PN-III-P1-1.2-PCCDI-2017-0224 (no. 77PCCDI/2018, DigiTech) within PNCDI III programme; the framework of the GNaC 2018 ARUT grant "Dezvoltarea tehnologiilor de tipărire 3D a pieselor complexe din materiale compozite", research Contract no. 3215 / 06.02.2019, with the financial support of the Technical University of Cluj-Napoca and HORIZON 2020 - DiCoMI, "Directional Composites through Manufacturing Innovation", GA Nr. 778068.

\section{References}

1. V. Ceclan, S. Grozav, N. Balc, Quality-Access to Success J, 13, 5 (2012)

2. M. N. Islam, B. Boswell, Int. J of Chem., Molecular, Nuclear, Mat. and Met. Eng., 10, 7 (2016)

3. J. Kuczmaszewski, I. Zagorski, O. Gziut, S. Legutko, G.M. Krolczyk, J of Mech. Eng., 63 (2017)

4. R. Zitoune, V. Krishnaraj, F. Collombet, Compos Struct 92, 5 (2010)

5. N. Panc, V. Bocanet, M. Bulgaru, C. Beldean, Acta Tech. Napocensis-Applied Math. and Mech., 57, 1 (2014)

6. A. Popescu, G. Marian Pop, M. Steopan, G. Conţiu, Trans Tech Pub., 808, (2015)

7. S.Y. Hong, I. Markus, W. C. Jeong, Elsevier Science, 41 (2001)

8. L.T. Tunc, Y. Gu, M.G. Burke, J Procedia CIRP, 45 (2016)

9. V. Bocanet and N. Panc, MATEC Web of Conf., 137 (2017)

10. J. Jerzy, I. Kuric, S. Grozav, V. Ceclan, Academic J of Manuf. Eng., 12, 1 (2014)

11. Inova Tools catalogue (2019) 